Syntax Idea: p-ISSN: 2684-6853 e-ISSN: 2684-883X

Vol. 3, No. 2, Februari 2021

\title{
PALEOPRODUKTIVITAS FORMASI TAPAK BANYUMAS BERDASARKAN BUKTI MIKROFOSIL
}

\section{Bayu Awifan Dwijaya, Romanus Edy Prabowo, Gentur Waluyo, Imam Prayitno dan Ardo Ramdhani}

Universitas Jenderal Soedirman dan PPPTMGB LEMIGAS (Pusat Penelitian dan

Pengembangan Teknologi Minyak dan Gas Bumi) Purwokerto, Jawa Tengah, Indonesia

Email: bayu.goldha@gmail.com,imam.prayitno@esdm.go.id

gentur.geologi1960@gmail.com dan ardoramdhani.id@gmail.com

\section{Abstract}

Tapak formation is a formation that is known to experience many changes in the ancient environment. This research was conducted in Tapak Formation, Mount Tugel, Banyumas Regency using bentonik and nannofosil foraminifera. Relative age analysis showed the sample age was around the initial pliocene, i.e. NN14 to no younger than NN15 (4.2 million years ago to lower than 3.5 million years ago). Paleoecological dynamics observed from abundance and diversity of microfossils experienced a decreased tendency from older samples to younger samples. Changes in paleoproductivity were observed based on primary and secondary productivity, where older samples tended to be higher than younger ones. Toc (Total Organic Carbon) content in older samples has a higher value than younger samples. The value of $\mathrm{CaCO} 3$ relatively increased in the younger direction, but in the A21N sample the percentage increased dramatically.

Keywords: fosi biodiversity; paleoecology; paleoproductivity

\begin{abstract}
Abstrak
Formasi Tapak merupakan formasi yang sedikit menyimpan informasi dikarenakan kondisinya yang cenderung banyak mengalami disturbansi. Penelitian ini dapat melengkapi informasi ilimiah yang tidak banyak diteliti pada Formasi Tapak serta bertujuan untuk merekonstruksi kodisi paleoproduktivitasnya menggunakan foraminifera bentonik dan nannofosil. Analisis umur relatif menunjukkan umur sampel sekitar pliosen awal, yaitu NN14 hingga tidak lebih muda dari NN15 (4,2 juta tahun yang lalu hingga lebih rendah dari 3,5 juta tahun yang lalu). Dinamika paleoekologi diamati dari kelimpahan dan diversitas mikrofosil mengalami kecenderungan yang menurun dari sampel lama ke sampel yang lebih muda. Perubahan paleoproduktivitas diamati berdasarkan produktivitas primer dan skunder, dimana sampel yang lebih tua cenderung lebih tinggi nilainya dari pada yang lebih muda. Kandungan TOC (Total Organic Carbon) pada sampel yang lebih tua memiliki nilai lebih tinggi dibandingkan sampel yang lebih muda. Nilai CaCO3 relatif meningkat ke arah yang lebih muda, tetapi pada sampel A21N persentasenya meningkat secara dramatis.
\end{abstract}

Kata kunci: biodiversitas fosi; paleoekologi; paleoproduktivitas 


\section{Pendahuluan}

Organisme selalu berinteraksi dengan lingkunganya, dan interaksi ini merupakan sistem ekologi yang berkesinambungan. Perubahan pada lingkungan yang terjadi menyebabkan perubahan dalam sistem ekologi dan struktur organisme dalam lingkungan tersebut. Dalam pengukuran perubahan lingkungan purba dapat menggunakan pendekatan mikropaleontologi untuk merekonstruksi keberadaan organisme serta lingkungan di masa lalu dengan menggunakan mikrofosil bercangkasng seperti foraminifera dan nannofosil. Bukti mikrofosil, dapat digunakan untuk merekonstruksi masukan bahan organik purba yang terdapat dalam batuan. Fokus utama penelitian ini adalah pengungkapan informasi paleoekologi mikrofosil dan kaitanya dengan paleoproduktifitas yang terdapat dalam batuan sedimen Formasi Tapak Gunung Tugel dalam Cekungan Banyumas.

Cekungan Banyumas terletak di Jawa Tengah bagian selatan. Letak cekungan di daerah Banyumas sehingga disebut Cekungan Banyumas yang terdiri dari beberapa sub cekungan. Cekungan Banyumas termasuk kawasan dinamis yang mempunyai beberapa formasi batuan dengan umur geologi waktu pengendapan beragam, sehingga memberi gambaran ekologi berupa fluktuasi lingkungan berbagai periode waktu dari masa lampau hingga sekarang. Salah satu formasi batuan pada Cekungan Banyumas yang menarik untuk diteliti adalah Formasi Tapak. Penyusun formasi ini berupa batupasir kasar berwarna kehijauan dan konglomerat serta dijumpai breksi andesit. Bagian atas terdiri atas batupasir karbonatan dan napal berwarna hijau yang mengandung pecahan moluska. Formasi ini memiliki ketebalan $500 \mathrm{~m}$ dan diendapkan pada lingkungan transisi sampai laut (Djuri, Samodra, Amin, \& Gafoer, 1996). Penelitian ini menggunakan sampel sedimen yang diambil di area penambangan Gunung Tugel untuk melihat perubahan struktur komunitas mikrofosil yang terbentuk dengan kondisi paleoekologi dan pengaruh paleoproduktifitas ekosistem yang ditinjau dari masukan beban organik serta kandungan oksigen purba menggunakan fungsi transfer. Penelitian ini dapat melengkapi informasi ilimiah yang tidak banyak diteliti pada Formasi Tapak serta bertujuan untuk merekonstruksi kodisi paleoproduktivitasnya menggunakan foraminifera bentonik dan nannofosil.

\section{Metode Penelitian}

Penelitian ini dilakukan dengan metode kuantitatif dengan data yang diperoleh berasal dari data hasil pengukuran langsung berupa struktur dan komunitas fosil serta data fungsi transfer. Janis data yang di dapat pada struktur dan komunitas fosil adalah data rasio, data tersebut setelah dianalisis normanlitas datanya adlah jenis data parametrik. Variabel yang didapat untuk analisis ini berasal dari transfer fungsi berbagai pendekatan purba, sehingga banyaknya jumlah variabel yang digunakan merujuk analisis menggunaka analisis multivariat. 
Bayu Awifan Dwijaya, Romanus Edy Prabowo, Gentur Waluyo, Imam Prayitno dan Ardo Ramdhani

\section{Lokasi dan Waktu}

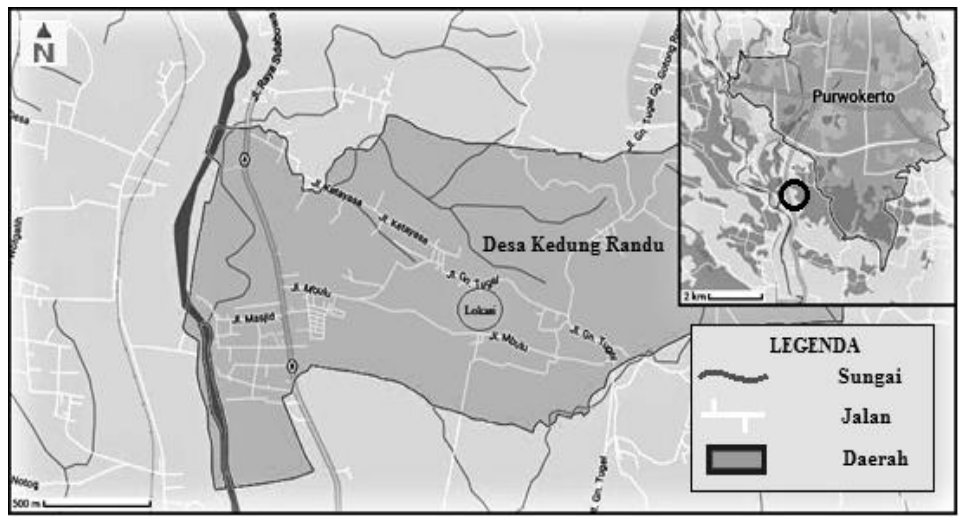

Gambar 1

Peta Lokasi Pengambilan Sampel berdasarkan Citra Google 2015

Penelitian ini dilakukan di daerah penambangan batu di Gunung Tugel, Banyumas dan Laboratorium Nannofosil PPPTMGB LEMIGAS (Pusat Penelitian dan Pengembangan Teknologi Minyak dan Gas Bumi) selama bulan Februari hingga Maret 2015. Lokasi penelitian diketahui sebagai Formasi Tapak Cekungan Banyumas dengan koordinat 7。28'34.19" LS dan 109 14' 03.16" BT yang merupakan singkapan bentuk outcrop pada ketinggian $70 \mathrm{~m}$ dpl, dengan jarak lintasan sejauh $180 \mathrm{~m}$ dan total ketebalan sedimen setelah dikoreksi sebesar 7,45 $\mathrm{cm}$. lokasi ini termasuk dalam wilayah eks-Karesidenan Banyumas, Jawa Tengah bagian selatan.

\section{Teknik Pengambilan Sampel dan Cara Kerja}

Penelitian ini mencari data berupa data nominal dan data ordinal. Data nominal berupa pemerian yang didapatkan di lapangan dalam bentuk pemerian batuan dan litologi satuan batuan yang didapatkan di lapangan. Data ordinal diperoleh dengan mengamati paleoekologi pada struktur komunitas fosil foraminifera bentonik dan nannofosil serta variabel paleoenvironment. Paleoenvironment merupakan variabel lingkungan yang diprediksi akan mempengaruhi kondisi paleoekologi. Paleoenvironment yang dievaluasi meliputi Total Organic Carbon (TOC), $\mathrm{CaCO}_{3}$, Oksigen Purba. Paleoekologi yang diamati adalah struktur dan komposisi fosil foraminifera bentonik dan nannofosil, paleoproduktifitas primer serta paleoproduktifitas sekunder. Penelitian ini menggunakan metode survei dengan teknik pengambilan sampel yang dilakukan berupa stratified sampling melalui pengukuran penampang stratigrafi (PPS). Sampel diambil sepanjang $180 \mathrm{~m}$ dengan 36 titik sampel. Selanjutnya batuan tersebut dideskripsikan sebagai sampel dalam pemerian terhadap setiap fasises litologi yang ditemukan.

Preparasi dilakukan untuk mendapatkan mikrofosil. Keberadaan foraminifera bentonik dan nannoplankton akan diamati dibawah mikroskop setelah sampel dipreparasi. Dalam preparasi foraminifera diperlukan sampel sedimen 
sebanyak 200 gr yang dibungkus menggunakan kain dan selanjutnya ditumbuk menggunakan palu. Setelah ditumbuk sampel dipindahkan ke dalam mangkok alumunium lalu diberi larutan $\mathrm{H}_{2} \mathrm{O}_{2}$ (Hidrogen Peroksida) 30\%. Setelah itu sampel dicuci dengan air yang mengalir di atas tiga saringan yang dari atas ke bawah berukuran 80-120-140 mesh, hasil ketiga saringan yang tersaring dimasukkan kedalam mangkuk porselin dan dikeringkan di dalam oven $\left( \pm 50^{\circ} \mathrm{C}\right)$. Sampel residu kering siap untuk dipicking, diamati dan dideterminasi menggunakan mikroskop setereo binokuler.

Preparasi nannofossil diperoleh dengan menimbang \pm 10 gram sampel yang masih segar kemudian dibersihkan dari kotoran yang masih menempel dengan cutter. Sampel ditumbuk menggunakan mortar dan pastel sampai halus, sebagian sampel dimasukan kedalam tabung kemudian diberi akuades dan diputar menggunakan alat vibrator ultrasonik vortex kurang lebih 5-10 menit hingga larut. Biarkan suspensi mengendap selama \pm 5 menit dan dibuang airnya, dilakukan pengulangan satu kali ditambah lagi akuades dan dilarutkan kembali. Setelah mengendap dengan pipet kecil atau sedotan diteteskan 1-2 tetes suspensi larutan diatas gelas objek kemudian diteteskan larutan Cellosiece sekitar 1-2 tetes dan diratakan agar sampel kering tidak retak. Sampel dipanaskan diatas hot-plate (thermoscientific) sampai airnya hilang atau kering. Setelah kering teteskan lem entelan 1 tetes kemudian ditutup dengan cover glass dan ditunggu hingga kering. Selanjutnya diamati dibawah mikroskop polarisasi dan diidentifikasi.

Evaluasi geokimia berupa karbon sedimen bertujuan untuk mengetahui kandungan karbon yang diperkirakan berhubungan erat dengan produktifitas dan keberadaan fosil foraminifera bentonik maupun nannofosil. Evaluasi karbon dilakukan, meliputi total karbon, total karbon organik dan total karbon inorganik. Sampel yang akan dievaluasi dibersihkan dan dikeringkan dengan suhuh $90{ }^{\circ} \mathrm{C}$ selama 24 jam, kemudian sampel ditumbuk hingga halus. Evaluasi Total Karbon dilakukan dengan menimbang $100 \mathrm{mg}$ sampel sedimen yang kemudian dibakar menggunakan LECO IR 212 analyser pada suhu 1050 C. Selama proses pembakaran akan menghasilkan depletor $\mathrm{CO}_{2}$, kemudian diukur dengan infra red detector. Evaluasi Total Karbon Inorganik dilakukan dengan menimbang $100 \mathrm{mg}$ sampel yang diukur dengan melarutkan sampel dengan $\mathrm{HCl}$ di dalam calcimetric bomb. $\mathrm{CO}_{2}$ yang dihasilkan dari pencernaan $\mathrm{HCl}$ dihitung dengan pressure measurement. Evaluasi Total Karbon Organik dihitung antara selisih total karbon dengan total karbon inorganik dengan asumsi bahwa semua karbonat merupakan kalsit $\left(\mathrm{CaCO}_{3}\right)$ alami yang mempresentasikan sumber karbon inorganik (Dijk et al., 2019).

Diversitas spesies fosil baik foraminifera bentonik mauapun nannofosil dihitung menggunakan indeks diversitas Shannon Wiener. Principal Component Analysis (PCA) atau juga dikenal dengan analisis komponen utama. PCA dalam penelitian ini untuk membangkitkan nilai analasis dari variabel surrogate yang digunakan dalam mentukan spesies penciri produktifitas primer purba. 
Bayu Awifan Dwijaya, Romanus Edy Prabowo, Gentur Waluyo, Imam Prayitno dan Ardo Ramdhani

Paleoproduktivitas dapat diamati dengan mengukur kelimpahan dari spesies yang diindikasikan sebagai penciri produktivitas. Dimana akan dibagi menjadi dua kelompok sebagai spesies penciri kaya nutrisi dan sebagai spesies penciri miskin nutrisi menggunakan analisis kuantitatif hasil PCA. (Herrle, Pross, Friedrich, Kößler, \& Hemleben, 2003)

$$
\text { Prod } p=\frac{H f}{H f+L f}(1)
$$

Keterangan :

$\mathrm{H} f \quad$ : spesies penciri High fertility

Lf : spesies penciri Low fertility

Prod $\mathrm{p}$ : Produktifitas primer purba

Kelimpahan relatif foraminifera bentonik epifauna dan infauna dapat digunakan sebagai proxy terhadap tingkat aliran bahan organik yang berpengaruh terhadap produktifitas purba yang tertangkap dalam jerapan sedimen. Berdasarkan pengmatan cangkang (test) eksternal secara simetri dan geometri, foraminifera bentonik terbagi menjadi 7 kelompok menurut (Mattioli, Pittet, Petitpierre, \& Mailliot, 2009).

Morphogroup A, unisrial, elongated dan spesies yang termasuk kelompok ini berasal dari genera Paralingalina dan Ichthyolaria. Morphogroup B, elongated, dan foraminifera berbentuk Spindle seperti Eoguttalina. Morphogroup C, bentuk uniserial, elongated dan cylindrical (Prodentalina, Mesodentlina, Pseudonodosaria, Nodosaria dan Marginulina). Morphogroup D, bentuk flat, evolute dan planispiral (Astacolus dan Lenticulina). Morphogroup E, foraminifera berbentuk Lenticuler, strongly biconvex, involute, planispiral (Lenticulina). Morphogroup F, cangkang discoid proloculus yang diikuti dengan tidak terbaginya kamar tubuler kedua (Spirillina). Morphogroup G, bentuk trochospiral dan conical (Epistomina, Reinholdella). Berdasarkan kesamaan morfologi dengan taxa recent, maka dapat diperkirakan bahwa morphogroup A, B dan C merupakan kelompok foraminifera bentonik infauna sedangkan morphogroup D, E, F dan G merupakan kelompok foraminifera bentonik epifauna.

Kandungan oksigen purba merefleksikan keadaan lingkungan kaitanya dengan keberadaan beban organik perairan dalam suatu ekosistem purba. Semakin tinggi kandungan bahan organik dalam suatu perairan diperkirakan dapat menurunkan kandungan oksigen suatu perairan. Fungsi transfer oksigen dapat diterapkan sebagai proxy terhadap kandungan oksigen di masa purba menurut formula berikut (Kouwenhoven \& Van der Zwaan, 2006):

$$
\left(\mathrm{O}_{2} \mu \frac{\mathrm{Mol}}{\mathrm{lt}}\right)=7.9602+5.95(\% \text { taxa Oksifilik })
$$

Keterangan:

Taksa Oksifilik: merupakan taksa yang menyukai lingkungan dengan kandungan oksigen tinggi 


\section{Hasil dan Pembahasan}

Hasil observasi lapangan didapatkan litologi berupa batupasir berwarna kehijauan dan abu-abu sehingga membentuk Satuan Batu Pasir. Tipe sedimen yang didapatlan di lapangan secara detil meliputi batu pasir kasar, batu pasir sedang, batu pasir halus, batu pasir-lempungan, batu lempung pasiran dan batu lempung. Beberapa sampel, ditemukan cangkang makro dari Moluska maupun Bivalvia, hal ini mengindikasikan bahwa lingkungan purba pada sampel tersebut dalam kondisi lingkungan perairan.

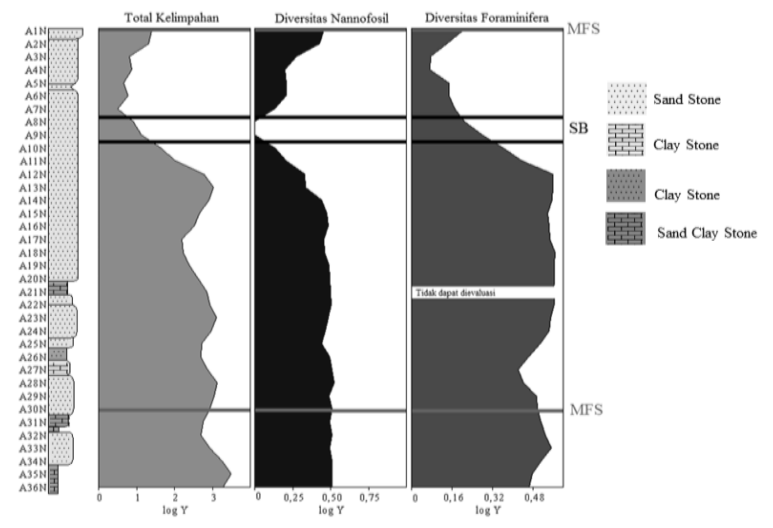

Gambar 2

Grafik Litologi dan plot log kelimpahan dari total kelimpahan, diversitas nannofosil serta diversitas foraminifera bentonik

Berdasarkan grafik pada gambar 2 (total kelimpahan: gabungan antara komunitas nannofossil dengan foraminifera bentonik) maka dapat diketahui bahwa kondisi tersebut terjadi karena perubahan muka air laut yang menyebabkan penurunan jumlah komunitas fosil. Maximum Flooding Surface (MFS) dan Sequence Boundary (SB) dapat dideteksi dengan puncak tertinggi dan lembah terendah dari kemunculan dan/atau frekuensi kemunculan mikrofosil (Cohen, 2017). Fosil cenderung sensitif terhadap perubahan dinamika sedimentasi dalam suatu cekungan, pengembangan data dalam komunitas suatu fosil dapat digunakan untuk mengetahui sistem perubahan eustasi dan mengkarakteristik sistem saluran dan batas sekuens (Cohen, 2017), (Arvestal \& Willman, 2020). Kondisi dalam penelitian ini mengalami pendangkalan (regresi) yang meyebabkan hilangnya spsies dari komunitas nannofossil maupun fosil foraminifera bentonik. Berdasarkan kelimpahan total baik komunitas nannofosil maupun fosil foraminifera bentonik, dimulai dari A10N samapai A1N, terlihat menurun (lihat lampiran 4-7 dan lampiran 13-16). Hal ini sesuai dengan kondisi yang berbanding terbalik terhadap data fosil darat pada tempat yang sama dengan penelitian ini (Suedy, 2012). (Suedy, 2012) menjelaskan bahwa pada sampel yang ditelitinya pada formasi dan lokasi yang sama, memperlihatkan trend berbanding terbalik dengan objek pollen yang memiliki arti sama dengan penelitian ini, yaitu lapisan yang muda (sampel dengan nomor kecil, misalnya A1N) cenderung semakin membentuk daratan (regresi). Berdasarkan data, baik hasil observasi mikroskopis nannofossil maupun fosil foraminifera bentonik, maka dapat disimpulkan bahwa terdapat tiga kelompok kejadian dalam sikuens stratigrafi ini. Lingkungan laut purba dalam penelitian ini mengalami dua 
Bayu Awifan Dwijaya, Romanus Edy Prabowo, Gentur Waluyo, Imam Prayitno dan Ardo Ramdhani

kali MFS dan satu SB. MFS adalah Bidang genang laut maksimal yang terbentuk pada saat fase genang laut maksimum. SB adalah suatu bidang keselarasan dan keselarasan padanannya yang terjadi selama jangka waktu penurunan relatif permukaan laut ((Armstrong \& Brasier, 2013)), (Arvestal \& Willman, 2020).

Hasil observasi mikroskopis yang telah dilakukan di Formasi Tapak Kabupaten Banyumas daerah Gunung Tugel menunjukan bahwa terdapat 41 spesies dari 12 famili nannofosil dengan jumlah individu teramati sebanyak 4844 individu. Famili tersebut meliputi Pontosphaeraceae, Rhabdosphaeraceae, Thoracosphaera, Calyptrosphaeracae, Cocolithaceae, Syracopsphaeraceae, Sphenolithaceae, Calcidiscaceae, Ceratolithaceae, Noelaerhabdaceae, Discoasteraceae dan Helicosphaeraceae. Formasi Tapak ini diprediksi merupakan daerah payau di saat lampau yang dibuktikan dengan kemunculan spesies penciri lingkungan payau seperti Helicopsphaera carteri, Reticulufenestra minuta dan Calcidiscus leptoporus.

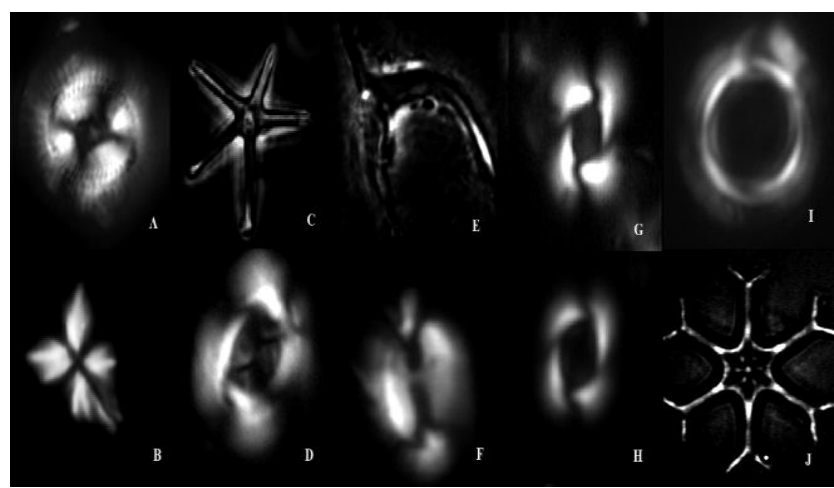

Gambar 3

Perbesaran 1000X menggunakan mikroskop polarisasi $A$. Cocolithus pelagicus; $B$.

Sphenolithus abies; C. Discoaster asymetricus; D. Reticulofenestra pseuoumbilicus; $E$ Amaroulithus tricorniculatus; F. Helicosphaera selii; G. Pseudoemiliana ovata; H. Reticulofenstra minutula; I. Umbilicosphaera rotula; J. Discoaster variabilis

Hasil analisis Indeks Shanon untuk nannofosil memperlihatkan bahwa diversitas sampel dalam penelitian ini menjelaskan bahwa lingkungan purba saat lampau pada penelitian ini realtif stabil pada sampel yang lebih tuda, kemudian diversitas menurun pada sampel yang lebih muda. Dari keseluruhan sampel didapatkan 6 spesies dengan nilai INP >10\% yaitu, Sphenolithus abies (36.22\%), Cocolithus pelagicus (14.68\%), Helicopsphaera selii (14.23\%), Reticulufenestra minutula (10.1\%), Ponthopshaera ovata (18.44\%) dan Umbilicosphaera rotula (10.41\%). Spesies-spesies tersebut merupakan spesies yang sanggup tinggal di berbagai pengaruh dan perubahan lingkungan dalam studi ini.

Hasil observasi mikroskopis dengan nilai dari Indeks Nilai Penting pada foraminifera bentonik diatas $10 \%$ meliputi, Ammonia becarii, Rotalinoides compressiuscula (synonym name: Pseudorotalia gaimardii), Quinqueloculina seminula, Nonion sp. dan Asterorotalia pulchella. Individu foraminifera bentonik yang diobservasi dibawah mikroskop sebanyak 54.933 individu, yang termasuk dalam 67 spesies, 14 ordo dan 30 famili dari foraminifera bentonik, yang meliputi, Rotaliidae, 
Hauerinidae, Nonionidae, Elphidiidae, Ellipsolagenidae, Bolivinidae, Stilostomellidae, Rhabdaminnidae, Soritidae, Spirillinidae, Alveolinidae, Buliminidae, Uvigerinidae, Fursenkoinidae, Plectofrondiculariidae, Amphisteginidae, Vaginulinidae, Orbitolinidae, Siphonogenerinoididae, Planulinidae, Cibicididae, Spiroloculinidae, Uvigerinidae, Calcarinidae, Elphidiidae, Cassidulinidae, Cassidulinidae, Siphonogenerinoididae, Nodosariidae dan Bolivinidae.

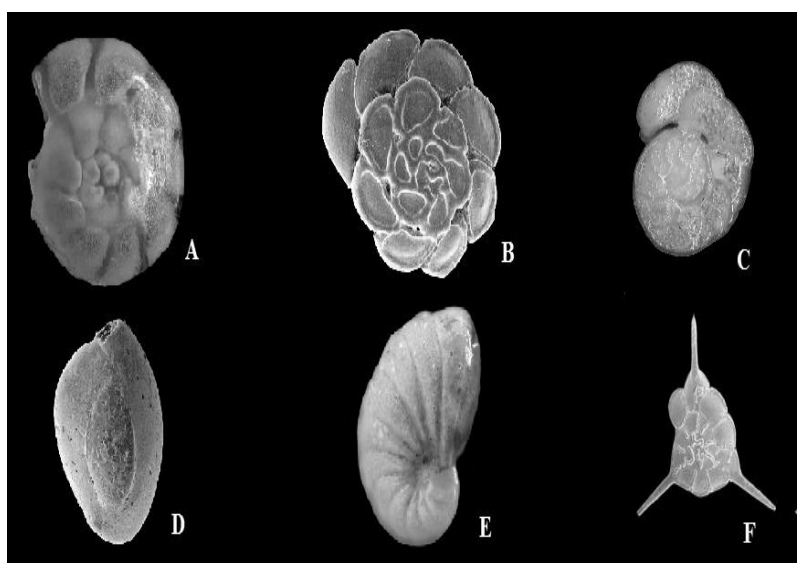

Gambar 4

Perbesaran 40X menggunakan mikroskop stereo A. Ammonia becarii; B. Rotalinoides gaimardii; C. Cibicides sp.; D. Quiqueloculina seminula; E. Nonion sp.; F. Asterorotalia pulchella

Hasil analisis indeks Shanon untuk foraminifera bentonik memperlihatkan bahwa diversitas yang cenderung rendah terdiri dari A1N-A8N dan A10N. Diversitas sedang meliputi A9N dan A27N. Sampel A21N tidak dapat dievaluasi karena tidak ditemukan sama sekali kemberadaan mikrofosil foraminifera sehingga data paleoekologi tidak representatif (lihat pembahasan geokimia). Diversitas tinggi merupakan sampel yang tidak disebutkan dari sampel diatas sebelumnya, hal ini menjelaskan bahwa lingkungan purba saat lampau pada penelitian ini realtif stabil pada sampel yan lebih tua, kemudian mengalami penurunan diversitas pada sampel yang lebih muda.

Hasil analisis umur relatif menunjukan bahwa sampel berada pada selang NN14tidak lebih muda dari N15. Hal ini dicirikan dengan kemunculan D. asymetricus sebagai penciri batas bawah NN14 dan A. tricorniculatus sebagai batas atas NN14, sedangkan S. abies dan R. pseudoumbilicus sebagai penciri batas umur relatif yang tidak lebih muda dari NN15 (gambar 5). Kondisi lingkungan pengendapan pada sampel penelitian ini tepat berada dibatas fasies antara pliosen awal bagian atas yang memisahkan fasies dengan pliosen akhir, hal tersebut dikarenakan terjadinya MFS (Maximum Flooding Surface) setelah sebelumnya terbentuk SB (Sequence Boundary) atau di kenal dengan susut laut (lihat gambar 2). Hal tersebut sesuai dengan laporan (Cornée et al., 2016) yang menunjukan susut laut pada kala pliosen telah terjadi lima kali, dimana salah satunya ada pada pliosen awal bagian atas yang dicirikan dengan kejadian susut laut sebanyak dua kali. 
Bayu Awifan Dwijaya, Romanus Edy Prabowo, Gentur Waluyo, Imam Prayitno dan Ardo Ramdhani

Lingkungan pengendapan dianalisis berdasarkan kemunculan spesies indikator foraminiera bentonik. Hasil penelitian menjelaskan bahwa lokasi sampel penelitian mengalami perubahan batrimetri purba dalam pembentukan lingkungan pengendapan berdasarkan fosil yang telah ditemukan selama observasi laboratorim. Perubahan tersebut terjadi dari tua ke-muda dimulai dari inner meritic yang kemudian berselangseling dengan middle neritic. Perubahan tersebut berangsur-angsur hingga berubah menjadi area perselingan litoral-supralitoral. Hal ini terjadi karena saat Kala Pliosen bumi mengalami penurunan suhu yang sangat signifikan, kondisi ini umum di kenal sebagai waktu pra ice age. Kondisi dimana seluruh permukaan air laut di bumi menyusut, dan mempengaruhi kondisi paleobatrimetri. Walaupun demikian perubahan tersebut tidak hanya dipengaruhi kondisi iklim global, melainkan juga dipengaruhi kemungkinan kemunculan tektonik lokal, dimana pada waktu yang sama, terbentuk gunung api purba di seluruh pulau jawa (dari miosen tengah hingga pliosen akhir) termasuk Gunung Slamet yang sekarang masih aktif dan diprediksi bertanggung jawab pada perubahan batrimetri saat pembentukan Pulau Jawa (dimulai dari pembentukan zama pra-tersier) (Forestier, 2007).

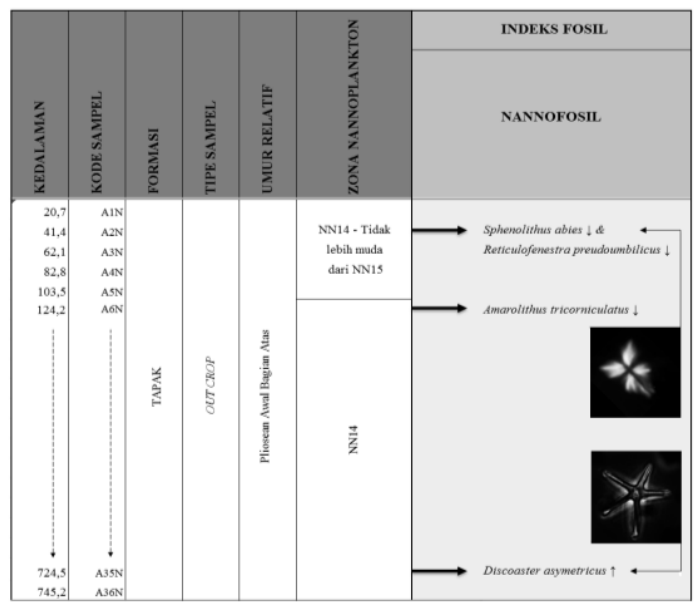

Gambar 5

Kolom umur relatif berdasarkan distribusi biostratigrafi, $S$. abies dan $R$. pseudoumbilicus (NN14-tidak lebih muda dari NN15) serta D. asymetricus (NN14)

Perubahan paleobatrimetri diketahui memang terjadi dari Pliosen hingga Plistosen (Haywood et al., 2016). Hal ini terjadi karena saat Kala Pliosen Pulau Jawa dipengaruhi kemunculan tektonik lokal, yaitu karena pengaruh sesar berdasarkan struktur dari pola meratus dan pola keraton, sehingga lokasi penelitian mengalami puncak tension dari pergerakan lempang yang terjadi di saat purba. Pada waktu yang sama, terdapat pembentukan gunung api (aktivitas gunung api/kejadian Mio-Pliosen) purba di seluruh pulau jawa (dari miosen tengah hingga pliosen akhir) termasuk Gunung Slamet yang diprediksi merupakan dampak dari sesar baik pola meratus dan pola keraton yang juga berimplikasi terhadap perubahan batrimetri (berupa pengangkatan lapisan/regresi, 
A36N-A8N) saat terjadi proses perubahan morfologi Pulau Jawa (dimulai dari pembentukan zama pra-tersier) ((Lumbanbatu, Hidayat, Sukapti, \& Patriani, 2014).

Spesies indikator untuk lingkungan litoral-supralitoral adalah kemunculan Ammonia becarii, spesies tersebut dikenal sebagai foraminifera yang kosmopolit terhadap pengaruh lingkungan, namun spesies ini cenderung lebih senang didaerah dengan pasokan nutrisi tinggi, oleh sebab itu, kemunculanya diprediksi karena lingkungan pengendapan saat lampau berada dekat dengan pengaruh daratan dan/atau influx air tawar (Bhadury \& Sen, 2020), (Takata, Hasegawa, \& Sonoda, 2019). Spesies indikator yang ditemukan dalam menentukan wilayah inner neritic meliputi, Amphistegina sp., Cibicides sp., Nonion sp., Asterorotalia pulchella, dan Quinqueloculina lamarckiana (Kholiq \& Wibowo, 2016). Spesies tersebut cenderung membutuhkan oksigen dengan sifatnya oksifilik (Cibicides sp.) dan kebutuhan nutrisi (Quinqueloculina lamarckiana dan Amphistegina sp.) yang cukup (Wilson, 2008), oleh sebab itu mereka digunakan sebagai spesies indikator untuk lingkungan inner neritic (lemigas). Lingkungan middle neritic pada penelitian ini dicirikan dengan kemunculan kelompok Nodosaria dan Dentalina (Kholiq \& Wibowo, 2016).

Perubahan lingkungan pengendapat dapat dilihat pada Gambar 6. Kolom tersebut menunjukan perubahan lingkungan dari laut hingga mengarah terjadinya pendangkalan atau daratan. Hal tersebut dijelaskan sebelumnya oleh beberapa laporan salah satunya (Suedy, 2012) bahwa hasil analisis palinologi di lokasi yang sama menunjukan tingkat kelembaban tinggi pada daratan mangrove yang terbentuk dan mengalami iklim basah berdasarkan polen mangrove yang ditemukan. Hal tersebut mendukung hasil penelitian ini, dimana iklim basah atau penurunan suhu memberikan dampak pada batrimetri purba.

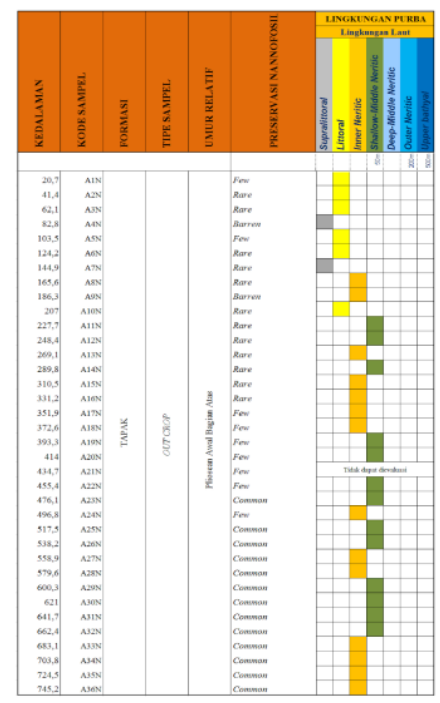

Gambar 6

Kolom lingkungan pengendapan berdasarkan nannofosil dan foraminifera bentonik

Hasil analisis PCA dari komunitas nannofosil menunjukan nilai variansi yang baik, yaitu sebesar $60.85 \%$ (Lihat Tabel 1). Hasil PC1 meiliki nilai eigen sebesar 
Bayu Awifan Dwijaya, Romanus Edy Prabowo, Gentur Waluyo, Imam Prayitno dan Ardo Ramdhani

7.2994, PC2 sebesar 4.0409 dan PC3 sebesar 2.6586. Nilai muatan variabel Surrogate pada masing-masing spesies dari ketiga PC dapat dilihat pada tabel 1. Ketiga PC tersebut diseleksi dan dicocokan berdasaarkna referensi terkait pengelompokan spesies penciri produktivitas, maka dapat diketahui bahwa PC2 adalah hasil analsis yang cocok dengan data dan referensi penunjang. Disebutkan bahwa R. minuta (Devellard Fionda, Gatto Motta, Magalhães-Ribeiro, Pedrosa Lemos, \& Wanderley, 2020) dan D. pentaradiatus (Tangunan et al., 2018) merupakan spesies penciri dengan fertilitas tinggi terhadap produktivitas lingkungan. Keberadaan mereka berpengaruh positif dengan laju pembentukan bahan organik dalam perairan. C. leptoporus merupakan spesies yang berhubungan dengan keberadaan bahan organik sebagai kelompok fertilitas rendah menurut (Galović, 2017).

Beberapa referensi tersebut menjelaskan kesesuaian data hasil PCA pada PC2 yang dapat digunakan untuk menentukan nilai produktivitas perairan. Nilai muatan spesies pada PC2 mengelompokan nilai negatif dan positif, dimana nilai diatas 0.5 baik positif (+) mauapun negatif (-) merupakan spesies yang dominan dan berpengaruh terhadap distribusi populasi data. Nilai diatas 0.4 namun dibawah 0.5 baik positif (+) maupun negatif (-) merupakan spesies asosiasi (tidak digunkan) (Reavie \& Chai, 2019). Dari tabel 1, maka dapat dikelompokan berdasarkan data tersebut dan referensi, bahwa R. minuta, D. pentaradiatus dan P. discopora merupakan spesies penciri produktivitas dalam kelompok fertilitas tinggi. H. carteri, Cd. leptoporus, D. altus dan D. variabilis dikelompokan sebagai penciri produktivitas sebagai kelompok fertilitas rendah.

Tabel 1

Muatan variabel surrogate dari hasil analisis PCA

\begin{tabular}{|c|c|c|c|}
\hline Spesies & Muatan & Spesies & $\begin{array}{c}\text { Variansi } \\
(\%)\end{array}$ \\
\hline 1 Cocolithus pelagicus & 0.74 & Discoaster asymetricus & 0.5131 .73 \\
\hline Helicosphaera carteri & 0.73 & Reticulofenestra minuta & 0.44 \\
\hline Helicosphaera selii & 0.82 & Discoaster pentaradiatus & 0.45 \\
\hline Calcidiscus. Macintyrei & 0.59 & Discoaster altus & 0.63 \\
\hline Sphenolithus abies & 0.90 & Discoaster variabilis & 0.67 \\
\hline Umbilicosphaera rotula & 0.72 & Reticulofenestra pseudoumbilicus & 0.57 \\
\hline Calcidiscus leptporus & 0.68 & Reticulofenestra minuta & 0.54 \\
\hline Pseudoemiliania ovata & 0.67 & Pontosphaera multipora & 0.51 \\
\hline 2 Helicosphaera carteri & -0.56 & Cocolithus pelagicus & $0.48 \quad 17.56$ \\
\hline Calcidiscus leptoporus & -0.54 & Pseudoemiliania ovata & 0.45 \\
\hline Reticulofenestra minuta & 0.66 & Reticulofenestra pseudoumbilicus & -0.47 \\
\hline Discoaster pentaradiatus & 0.70 & Reticulofenestra minutula & -0.42 \\
\hline Discoaster altus & -0.52 & Amarolithus tricorniculatus & -0.41 \\
\hline Discoaster variabilis & -0.58 & Pontosphaera discopora & 0.52 \\
\hline 3 Amarolithus tricorniculatus & 0.83 & Scyposphaera campanula & $0.81 \quad 11.56$ \\
\hline Pontosphaera multipora & 0.57 & & \\
\hline
\end{tabular}

Analisis NI atau produktivitas nannofosil (primer) dapat dilakukan dengan syarat kelimpahan diatas 100 individu (Wulff, Mutterlose, \& Bornemann, 2020), oleh sebab itu hanya 14 sampel yang dapat dianalisis, karena sisanya tidak memenuhi syarat. 
Kondisi tersebut, diprediksi tidak memiliki produktifitas purba primer laut karena sudah dipengaruhi faktor lingkungan darat atau air tawar, sehingga tidak cocok untuk analisis produktifitas purba primer laut. Hasil analisis dapat dilihat pada gambar 7. Produktifitas purba dasar perairan (produktifitas sekunder) dapat diamati berdasarkan proporsi relatif antara kemunculan infauna dan epifauna foraminifera bentonik. Hasil keseluruhan sampel berdasarkan pengamatan foraminifera dikelompokan dalam bentuk epifauna dan infauna, dengan nilai kelimpahan relatif epifauna sebesar $79.2 \%$ dan infauna sebesar 20.7\% . Rekonstruksi paleoproduktivitas purba dasar perairan dapat dilakukan dengan syarat kelimpahan foraminifera diatas 200 individu (Jonkers, 1984), oleh sebab itu sampel yang dianalisis hanya dimulai dari A11N hingga A36N. Sampel A1N hingga A10N tidak dapat dianalisis karena kurang memenuhi syarat merekonstruksi produktifitas purba dasar perairan dengan membandingkan proporsi kelimpahan spesies foraminifera berdasarkan padanan ekologinya baik epifauna maupun infauna. Foraminifera epifauna cenderung hidup diatas permukaan dasar perairan, sedangkan habitat foraminifera infauna berada dalam sedimen dasar perairan yang terkubur sepenuhnya atau sebagian di dalam sedimen. Padanan ekologi tersebut memisahkan habitat foraminifera bentonik secara signifikan, yang berpengaruh terhadap ketersediaan makanan bagi foraminifera tersebut. Ketersediaan makanan ini mempengaruhi distribusi dan kelimpahan secara spesifik bagi masing-masing kelompok foraminifera bentonik tersebut. Kelompok infauna merupakan kelompok foraminifera bentonik yang sangat bergantung dengan jumlah nutrisi yang jatuh ke dalam sedimen, apabila nutrisi (bahan organik) yang jatuh ke dasar sedimen relatif sedikit, maka foraminifera epifauna yang akan menggunakanya telebih dahulu, kondisi tersebut memungkinkan kelompok epifauna cenderung lebih melimpah dibandingkan kelompok infauna. Pola dinamika seperti ini yang digunakan ahli paleontologi dalam merekonstruksi perubahan lingkungan purba (Rodrigues, Pivel, Schmitt, de Almeida, \& Bonetti, 2018).

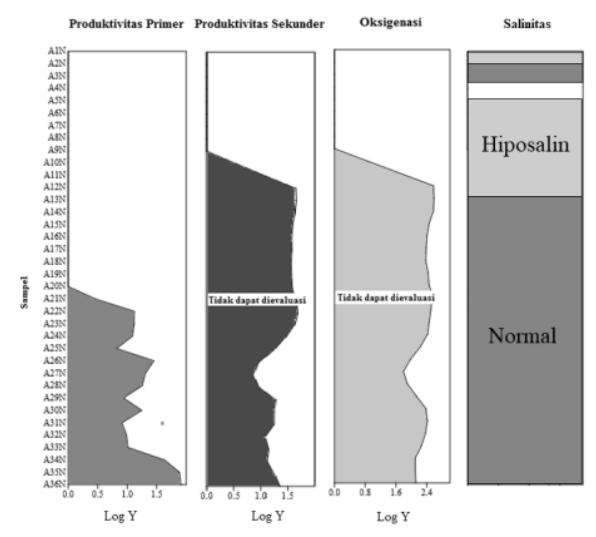

Gambar 7

Grafik evaluasi paleoekologi menggunakan proxy mikrofosil dan proporsi kelimpahan relatif hasil analisis cluste

Menurut (Rodrigues et al., 2018), foraminifera bentonik dapat digunakan untuk Total Organic Carbon (TOC) didefinisikan sebagai jumlah karbon organik yang dinyatakan dalam bentuk prosentase berat dari batuan kering (dry rock). Karbon organik 
Bayu Awifan Dwijaya, Romanus Edy Prabowo, Gentur Waluyo, Imam Prayitno dan Ardo Ramdhani

yang dimaksud merupakan karbon yang berasal dari zat organik dan bukan berasal dari karbonat (misalnya gampingan) Terdapat nilai TOC minimum untuk menyatakan suatu batuan sedimen dapat menjadi batuan induk. Hasil analisis TOC yang telah dilakukan menunjukan angka dimulai dari $0.143 \%$ (terendah) hingga $0.513 \%$ (tertinggi) A7N, A14N, A21N A28N tergolong berpotensi rendah, sedangkan A35N tergolong dalam sedikit berpotensi. Dapat dilihat pada gambar 8 yang menunjukan bahwa sampel A35N (sampel tua) cenderung memiliki nilai TOC yang lebih tinggi dibanding sampel yang lebih muda. Hal tersebut mengindikasikan bahwa bahan organik yang dievaluasi dengan uji TOC lebih banyak terbentuk ketika lingkungan pengendapan berbentuk laut dengan kedalaman perselingan inner neritic-shallow middle neritic (A28N dan A35N). Kondisi lingkungan perselingan litoral-supralitoral cenderung semakin berkurang dari nilai TOC yang dihasilkan (A7N). Kondisi ini diperkuat dengan data hasil analisis sebelumnya bahwa lokasi penelitian di masa pembentukan A7N-A28N (hasil geokimia dan paleobatrimetri) merupakan lokasi yang mengalami susut laut, sehingga memungkinkan penurunan produktifitas dan bahan organik.

Sampel A7N yang diprediksi (Suedy, 2012) (setelah penyelarasan lapisan) merupakan daerah transisi, dan berdasarkan hasil uji TOC dalam penelitian ini, menjelaskan bahwa lingkungan transisi disaat itu masih belum efektif memberikan pengaruh terhadap produktifitas ekosistem dikarenakan merupakan kondisi suksesi primer bagi lingkungan purba tersebut, sehingga nilai TOC yang ada masih relatif sangat sedikit, namun produktifitas pada awal suksesi ini sudah mulai berlangsung dalam nilai yang rendah $(0.143 \%)$. Bahan organik yang dievaluasi dengan uji TOC dari sampel A7N ini kemungkinan berasal dari darat dan/atau perairan tawar atau bisa jadi berasal dari campuran antara darat dan lautan, karena dibuktikan dari hasil evaluasi produktifitas primer purba laut dan produktifitas sekunder purba laut yang memiliki trend menghilang disampel tersebut.

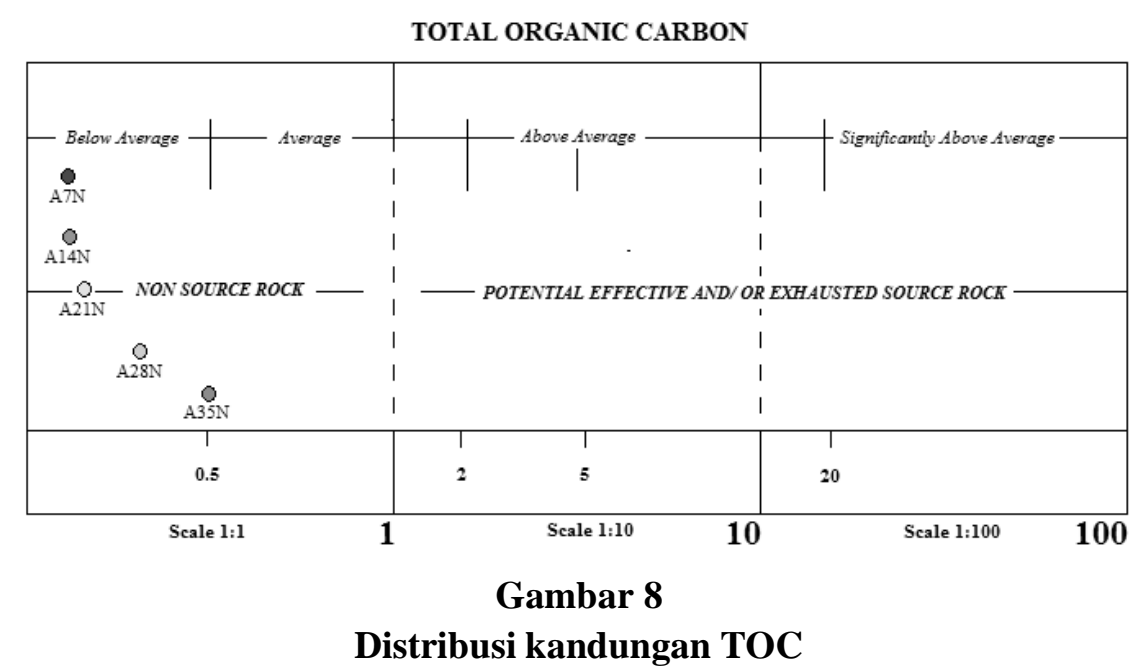

Hasil evaluasi $\mathrm{CaCO} 3$ dimulai dari $32.101 \%$ (terendah) pada $\mathrm{A} 28 \mathrm{~N}$ hingga $89.930 \%$ (tertinggi) pada $\mathrm{A} 21 \mathrm{~N}$. CaCO3 merupakan salah satu unsur pembentuk batu 
gamping. $\mathrm{CaCO} 3$ merupakan salah satu komponen penting dalam pertumbuhan nannofosil dan foraminifera dengan material cangkang hyaline, karena selama pertumbuhan dan reproduksi mereka membutuhkan kalsium karbonat sebagai bahan dasar pembentukan cangkang. $\mathrm{CaCO} 3$ yang dimaksud ini adalah struktur yang diobservasi dalam analisis struktur komunitas nannofosil, foraminiera bentonik bercangkang hyaline dan kandungan kadar gampingan yang ada dalam batu gamping.

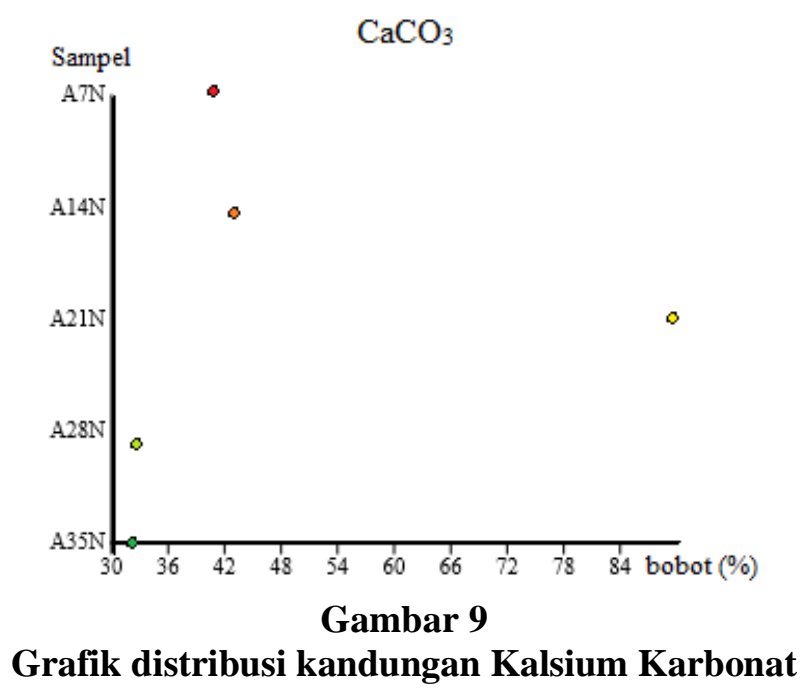

Sampel A14N memiliki kadar TOC yang rendah dan kadar CaCO3 yang relatif stabil. Hal tersebut menjelaskan bahwa sampel diprediksi dalam memiliki laju asimilasi yang rendah, dan dapt diprediksi bahwa lingkungan tidak menguntungkan dalam proses asimilasi dan/atau kadar $\mathrm{CO}$, hal tersebut dapat dikonfirmasi pada hasil analisis sebelumnya yang menjelaskan bahwa pada sampel ini cenderung mengalami susut laut yang diduga berkaitan dengan pengangkatan tektonik (Patria \& Hall, 2018), namun perubahanya secara dinamis dan drastis karena pada kala pliosen bumi mengalami pemanasan diatas suhu normal bumi saat ini yang menyebabkan dinamika eustasi dan paleobatrimetri (Dumitru et al., 2019). Sampel A7N memiliki nilai TOC dan CaCO3 yang serupa dengan A14N, namun perlu diketahui bahwa pada hasil analisis TOC sebelumnya telah dijelaskan, sampel A7N merupakan sampel dimana kondisi perairan tawar dan/atau darat telah mendominasi. Hal tersebut juga perlu digaris bawahi bahwa keberadaan $\mathrm{CaCO} 3$ yang dihasilkan bersumber dari air tawar (hyposaline: hasil analisis nannofosil).

\section{Kesimpulan}

Dinamika paleoekologi yang diamati berdasarkan kelimpahan dan paleodiversitas baik fosil foraminifera bentonik maupun nannofosil secara umum memiliki trend menurun dari sampel tua ke sampel yang lebih muda. Analisis umur relatif menggunakan biomarker umur realtif untuk menghasilkan biozone nannofosil yang menunjukan sampel berumur pliosen awal bagian atas, yaitu NN14 hinga tidak lebih muda dari NN15 (4.2 juta tahun yang lalu hingga tidak lebih muda dari 3.5 juta tahun 
Bayu Awifan Dwijaya, Romanus Edy Prabowo, Gentur Waluyo, Imam Prayitno dan Ardo Ramdhani

yang lalu). Lingkungan pengendapan yang diamati berdasarkan paleobatimetri yang dianalisis menggunakan spesies penciri foraminifera bentonik dan PB rasio secara umum sampel berubah dari lingkungan shallow middle neritic menjadi supralitoral. Perubahan paleo produktifitas yang diamati berdasarkan produktifitas primer purba, produktivitas sekunder purba, oksigen, dan TOC menunjukan sampel bersifat dinamis dimana sampel lebih tua bersifat lebih tinggi produktifitasnya dan kemudian mengalami trend yang menurun hingga pada sampel yang lebih muda.

\section{BIBLIOGRAFI}

Armstrong, Howard, \& Brasier, Martin. (2013). Microfossils. USA: Blackweel Publishing

Bhadury, Punyasloke, \& Sen, Areen. (2020). Understanding impact of seasonal nutrient influx on sedimentary organic carbon and its relationship with Ammonia spp. in a coastal lagoon. Frontiers in Marine Science.

Cornée, Jean Jacques, Münch, Philippe, Achalhi, Mohammed, Merzeraud, Gilles, Azdimousa, Ali, Quillévéré, Frédéric, Melinte-Dobrinescu, Mihaela, Chaix, Christian, Moussa, Abdelkhalak Ben, \& Lofi, Johanna. (2016). The Messinian erosional surface and early Pliocene reflooding in the Alboran Sea: New insights from the Boudinar basin, Morocco. Sedimentary Geology, 333, 115-129.

Devellard Fionda, Anaiza Claudia Meira, Gatto Motta, André Luiz, Magalhães-Ribeiro, Claudia Maria, Pedrosa Lemos, Flávia Azevedo, \& Wanderley, Maria Dolores. (2020). Biostratigraphy and Paleoecological Inferences Based on Oligocene Calcareous Nannofossils from the Ceará Rise (ODP Leg 154, Site 929A): Equatorial Atlantic Ocean. Anuario Do Instituto de Geociencias, 43(1).

Dijk, Inge van, Barras, Christine, Nooijer, Lennart Jan de, Mouret, Aurélia, Geerken, Esmee, Oron, Shai, \& Reichart, Gert Jan. (2019). Coupled calcium and inorganic carbon uptake suggested by magnesium and sulfur incorporation in foraminiferal calcite. Biogeosciences, 16(10), 2115-2130.

Djuri, M., Samodra, H., Amin, T. C., \& Gafoer, S. (1996). Peta geologi lembar Purwokerto dan Tegal. Jawa, Skala, 1(100.000).

Dumitru, Oana A., Austermann, Jacqueline, Polyak, Victor J., Fornós, Joan J., Asmerom, Yemane, Ginés, Joaquín, Ginés, Angel, \& Onac, Bogdan P. (2019). Constraints on global mean sea level during Pliocene warmth. Nature, 574(7777), 233-236.

Forestier, Hubert. (2007). Ribuan Gunung, Ribuan Alat Batu: Prasejarah Song Keplek, Gunung Sewu, Jawa Timur. Kepustakaan Populer Gramedia.

Galović, Ines. (2017). Sarmatian calcareous nannofossil assemblages in the SW Paratethyan marginal marine environments: implications for palaeoceanography 
and the palaeoclimate. Progress in Oceanography, 156, 209-220.

Haywood, Alan M., Dowsett, Harry J., Dolan, Aisling M., Rowley, David, Abe-Ouchi, Ayako, Otto-Bliesner, Bette, Chandler, Mark A., Hunter, Stephen J., Lunt, Daniel J., \& Pound, Matthew. (2016). The Pliocene model intercomparison project (PlioMIP) phase 2: scientific objectives and experimental design. Climate of the Past, 12(3), 663-675.

Herrle, Jens O., Pross, Jörg, Friedrich, Oliver, Kößler, Peter, \& Hemleben, Christoph. (2003). Forcing mechanisms for mid-Cretaceous black shale formation: evidence from the Upper Aptian and Lower Albian of the Vocontian Basin (SE France). Palaeogeography, Palaeoclimatology, Palaeoecology, 190, 399-426.

Jonkers, Hendrik Albert. (1984). Pliocene benthonic foraminifera from homogeneous and laminated marls on Crete. Utrecht University.

Kholiq, M. Abdul, \& Wibowo, Ari. (2016). Penerapan Teori Tujuan Pemidanaan Dalam Perkara Kekerasan Terhadap Perempuan: Studi Putusan Hakim. Jurnal Hukum Ius Quia Iustum, 23(2), 186-205.

Kouwenhoven, T. J. vd, \& Van der Zwaan, G. J. (2006). A reconstruction of late Miocene Mediterranean circulation patterns using benthic foraminifera. Palaeogeography, Palaeoclimatology, Palaeoecology, 238(1-4), 373-385.

Le Hérissé, A., Steemans, Philippe, Wellman, C., \& Vecoli, M. (2014). Darriwilian (Middle-Ordovician) elements of primitive vegetation, marine palynomorphs and problematic microfossils, from the Saq/Qasim transitional beds in core QSIM 801, central Saudi Arabia. Discussion with eustatic and climatic events.

Lumbanbatu, Ungkap M., Hidayat, Suyatman, Sukapti, Woro Sri, \& Patriani, Emma Yan. (2014). Geologi Kuarter Dataran Pantai Jepara, Jawa TENGAH. Jurnal Geologi Dan Sumberdaya Mineral, 15(1), 25-39.

Martini, Erlend. (1971). Standard Tertiary and Quaternary calcareous nannoplankton zonation. Proc. II Planktonic Conference, Roma 1970, Roma, Tecnoscienza, 2, 739-785.

Mattioli, Emanuela, Pittet, Bernard, Petitpierre, Laurent, \& Mailliot, Samuel. (2009). Dramatic decrease of pelagic carbonate production by nannoplankton across the Early Toarcian anoxic event (T-OAE). Global and Planetary Change, 65(3-4), 134-145.

Patria, Adi, \& Hall, Robert. (2018). Oblique Intraplate Convergence of the Seram Trough, Indonesia. Bulletin of the Marine Geology, 33(1).

Rodrigues, André Rosch, Pivel, María Alejandra Gómez, Schmitt, Patricia, de Almeida, Fabiana Karla, \& Bonetti, Carla. (2018). Infaunal and epifaunal benthic foraminifera species as proxies of organic matter paleofluxes in the Pelotas Basin, 
Bayu Awifan Dwijaya, Romanus Edy Prabowo, Gentur Waluyo, Imam Prayitno dan Ardo Ramdhani

south-western Atlantic Ocean. Marine Micropaleontology, 144, 38-49.

Suedy, S. W. A. (2012). Paleorekonstruksi Vegetasi dan Lingkungan Menggunakan Fosil Polen dan Spora Pada Formasi Tapak Cekungan Banyumas Kala PlioPlistosen. IPB University Bogor.

Takata, Hiroyuki, Hasegawa, Shiro, \& Sonoda, Takeshi. (2019). Life history of Ammonia "beccarii" forma 1 (benthic foraminifera, Rhizaria) in Lake Saroma, northern Japan. Estuarine, Coastal and Shelf Science, 229, 106385.

Tangunan, Deborah N., Baumann, Karl Heinz, Just, Janna, LeVay, Leah J., Barker, Stephen, Brentegani, Luna, De Vleeschouwer, David, Hall, Ian R., Hemming, Sidney, \& Norris, Richard. (2018). The last 1 million years of the extinct genus Discoaster: Plio-Pleistocene environment and productivity at Site U1476 (Mozambique Channel). Palaeogeography, Palaeoclimatology, Palaeoecology, 505, 187-197.

Wilson, Shawn. (2008). Research is ceremony: Indigenous research methods. Fernwood Publishing.

Wulff, Lena, Mutterlose, Joerg, \& Bornemann, Andre. (2020). Size variations and abundance patterns of calcareous nannofossils in mid Barremian black shales of the Boreal Realm (Lower Saxony Basin). Marine Micropaleontology, 156, 101853. 